\title{
Neuraxis metastases from central nervous system tumors: a review of clinicopathological and radiographic characters of 198 cases in a single center
}

Hailong Liu

Capital Medical University Sanbo Brain Hospital

Junping Zhang

Capital Medical University Sanbo Brain Hospital

Yongqiang Liu

Guangzhou University of Chinese Medicine

\section{Youliang Sun}

Capital Medical University

\section{Cheng Li}

Capital Medical University Sanbo Brain Hospital

\section{Chunyu Gu}

Capital Medical University Sanbo Brain Hospital

\section{Haoran Wang}

Capital Medical University Sanbo Brain Hospital

\section{Hongwei Zhang}

Capital Medical University Sanbo Brain Hospital

Chunjiang Yu

Capital Medical University Sanbo Brain Hospital

Zhang Mingshan ( $\sim$ zhangms7606@hotmail.com )

Capital Medical University Sanbo Brain Hospital https://orcid.org/0000-0002-7163-5201

Research article

Keywords: Neuraxis metastases, survival, MRI, classification, operation

Posted Date: August 23rd, 2019

DOl: https://doi.org/10.21203/rs.2.13467/v1

License: (영 This work is licensed under a Creative Commons Attribution 4.0 International License. Read Full License 


\section{Abstract}

Background Neuraxis metastases (NM) from systemic and central nervous system (CNS) tumors have become increasingly common. However, a lack of systematic information restricts the development of the accurate diagnosis and treatment. The aim of this study is to facilitate the understanding of NM arising from CNS tumors in the largest cohort. Methods Based on the clinicopathological and neuroimaging findings, we retrospectively analyze the epidemiological characters, radiographic classification, therapeutic strategies and prognostic factors. Results A total of 198 cases are enrolled and the most common primary tumor is medulloblastoma (34.34\%). The median age is 15.0 years and the majority of NM $(79.29 \%)$ occur in the children and young adult groups. 149 (75.25\%) cases suffer from intracranial metastases, and 169 (85.35\%) have the intraspinal NM. The whole leptomeninges and cauda equine are the most preferential disseminated sites. Upon MRI parameters, the massive and miliary subgroup occur most frequently in the intracranial and intraspinal NM, respectively. Treatment includes surgery (21.71\%), chemotherapy alone (19.19\%), radiation alone $(10.10 \%)$ and combined therapy (55.56\%). Operations are performed in order to identify pathology and relive masses, as well as the triple chemotherapeutic scheme consisting of ifosfamide, carboplatin and etoposide is recommended to most of NM. The median overall survival is 11.6 months. The younger age, coexistence of NM with primary tumors, shorter interval from primaries to metastases, glioma, leptomeningeal seeding and nodal subtype on MRI are significantly associated with the poor prognosis. Conclusion In spite of the controversial therapies and poor outcomes, the neuroimaging classification and comprehensive treatment contribute to the efficient administration of NM.

\section{Background}

Because survival of patients with CNS tumors have been promoted, and sensitivity of examinations including $\mathrm{MRI}, \mathrm{PET} / \mathrm{CT}$ or CSF test have advanced, metastases have become an increasingly common complication of cancers [1-3]. Over the past decades, leptomeningeal metastases (LM) from systematic cancers have been widely reported, which only reflects the appearances of tumor cells in the leptomeninges or CSF cisterns [4, 5]. Actually, metastases from CNS tumors frequently occur at the ventricles or cerebrospinal parenchyma. Thus, it is suggested that neuraxis metastases (NM) should be defined as the disseminated lesions along the neuraxis including the leptomeninges, ventricular system and even cerebrospinal parenchyma [6]. NM from CNS tumors exist as a distinct entity due to the multiple pathological subgroups, the complexity of metastatic regional anatomical structures and interdisciplinary management. Given the lack of studies systematically demonstrating this devastating stage of brain tumors and the available literatures reporting only some individual series, a deeper understanding of the clinicopathological features across the whole spectrum of NM is necessary for the accurate diagnosis and optimal treatment.

MRI has been abundantly utilized as the effective tool for implementing the diagnosis and designing the operation plans [7]. Especially, the sensitivity and specificity of MRI with gadolinium (Gd) enhancement have been elevated contributing to detecting the inaccessible NM in the past years [8]. However, in recent studies, only a fraction of NM originating from glioma limits developing the neuroimaging classification in a comprehensive view and estimating the survival in a statistical manner [9-11]. Therefore, with the goal of 
updating the radiographic classification of NM, an illustrative review of MRI features will provide more meaningful refers to facilitate the precise diagnosis.

Studies have reported that patients with cancer metastases usually suffer from poor prognosis and the median survival is about half a year $[12,13]$. Interdisciplinary treatment including the gross-total resection, chemotherapy and radiation has been well-established. Moreover, the molecular reagents play the critical roles in targeting the NM from lung, breast or prostate cancers [14-16]. Nevertheless, consensus still lacks for standard therapeutic indications of NM. Additionally, some existing data is partially restricted to the LM from systematic cancers and little is known concerning the prognostic factors of patients with NM from CNS tumors $[17,18]$, which prompts us to demonstrate the management strategies by analyzing the neuraxis metastatic data.

Based on the clinical practice and informative materials in our single center, this study attempts to report the NM originating from CNS neoplasms through a retrospective analysis of 198 cases including 32 histopathological subgroups, which is the largest series documenting the demography, diagnosis and treatment.

\section{Methods}

\section{Study participates}

From April 2004 to June 2018, 198 Chinese patients bearing NM at Department of Neurosurgery and Neurooncology in Sanbo Brain Hospital Capital Medical University were enrolled in this study. All patients receiving treatment for primary CNS tumors underwent routine follow-up in the outpatient at 2-month interval for the first 6 months, then at 6-month interval for the next 2 years and annually thereafter for 5 years by utilizing the whole brain and spine MRI monitors, as well as hormone and tumor marker tests were additionally performed in patients with GCTs. Patients suffering from possible progression, such as the new or inexplainable symptoms and signs from primary tumors, would increase follow-up frequencies. When metastatic lesions were detected on MRI, patients would be submitted to NM database and receive the following treatment and follow-up. In addition, cases receiving only supportive care for primary or metastatic tumors were excluded in current study.

194 cases underwent operations for primary lesions, whose pathogenesis were independently confirmed by two neuropathologists and the other 4 cases with germ cell tumors (GCTs) were diagnosed according to symptoms, MRI presentations and laboratory examinations. Clinical information was obtained from medical records, which included gender, age, initial cancer-associated data (locations, surgery approaches and histopathology), the interval between primary diagnosis and NM, NM-associated data (neurological symptoms and signs, sites, treatment and response) and the date of death. All procedures for medical 
research about human subjects were approved by the Research Ethics Committee of Sanbo Brain Hospital Capital Medical University and written informed consent was obtained from each patient (or the children guardians).

\section{MRI interpretation}

The entire neuraxis MRI scans were performed in all cases and the results were interpreted independently by two neuroradiologists, who focused on the following interests: the location, size and shape, lesion boundary, T1/T2 weighted imaging signals, tumor enhancement, leptomeningeal or cisternal enhancement, cancerous homogeneity and presence/absence of hydrocephalus. The shape of metastases determined the neuroimaging classifications of NM. Neurological examinations were conducted at the time of diagnosis.

\section{Statistical analysis}

Data statistical handling was performed using SPSS 19.0 and GraphPad Prism 7.0 software, and qualitative data was shown as the case (percentage) and quantitative data were presented as the median (range). The statistical analysis should be generated by the major groups, but not the subgroup data because of the rarity of some disorders. Comparison of mean values between multiple groups was evaluated by $\chi^{2}$ test. The Pearson Chi-Square test was adopted in the groups with values being more than 5 and the Fisher exact test was used in the group with values being less than 5. Log-rank test was performed to detect the differences in the overall survival (OS) and the survival curves were estimated by the Kaplan-Meier method. The Cox proportional hazards model was utilized to determine the prognostic factors, of which the item with significant difference on univariate analysis was submitted to the multivariate evaluation. For all statistical methods, $p<0.05$ was accepted as statistical significance.

\section{Results}

\section{Epidemiological characteristics of NM}

Over the past 10 years, we have constructed the work-up based on our clinical practice and NCCN guidelines [19], showing that patients who were suspected with NM would receive neurological examination and MRI scans, then the confirmed NM cases were included into NM database and received the corresponding treatment and follow-up (Fig. 1). Accordingly, a total of 198 subjects were retrieved from the database accounting for about $1.20 \%$ of all homochronous CNS neoplasms. We summarized the general, clinicopathological and therapeutic parameters of participants in Table 1. All initial lesions including 32 pathological subtypes were divided into 192 (96.97\%) intracranial cases and $6(3.03 \%)$ intraspinal cases. There were 78 (39.39\%) patients with primary embryonal tumors occupying the most common incidence rate, followed by GCTs (19.19\%), glioma (17.68\%), ependymoma (7.58\%) and pineal parenchymal tumors (PPTs, $5.05 \%$ ). Among the embryonal tumors, the most commonly diagnosed was medulloblastoma (Table 1 ). 
The obvious gender preponderance existed in the males because cases with male tendency (medulloblastoma, GCTs and PPTs) occupied $58.59 \%$ of the entire cohort (Table 1). Across all the cases, the median age was 15.0 years (range, $0.5 \sim 71.0$ years). Furthermore, a majority of NM (79.29\%) occurred in the younger age group containing 96 cases in children group ( $<14$ years) and 63 cases in young adult group (14 $\sim 35$ years, Supplementary Table 1). In detail, the peak of incidence rate stayed in the $<10$-year age group, of which the males were two times higher than the females (Fig. 2A). This phenomenon showed significant difference compared with the metastases coming from systematic cancers because they assembled in the relatively old population $[4,20]$. The median follow-up period of 46.6 months (range, $0.5 \sim 153.0$ months). Similar to the incidence rate, Fig. 2B promoted an awareness of the peak mortality rate in the $<10$-year age group. However, note of worth was that the almost equal male-to-female mortality rate existed in the $<10-$ year age group in contrast to the predominant male incidence at the same age course (Fig. 2A and 2B).

Of the 198 cases, 149 (75.25\%) suffered from intracranial metastases, 169 (85.35\%) had the intraspinal NM and 87 had coexistence of intra-cranial/spinal metastases accounting for $43.94 \%$. The evidence grouped by anatomical regions suggested that a majority of intracranial NM located at the whole leptomeninges, followed by the ventricular system. And intraspinal NM were found more preferentially in the whole leptomeninges and cauda equine (Fig. 2C and 2D). However, the most common primary site stationed at the fourth ventricle because of the high proportion of medulloblastoma cases (supplementary Fig. 1A). The median interval from primary tumor to the first time NM was 18.4 months (range, $0 \sim 156.0$ months). Among them, $58(29.29 \%)$ patients with primary tumors presented the concurrent NM, of which the most common metastatic sites ranged by the fourth ventricle, sellar and parasellar regions. As shown in Fig. 2E, it was statistically significant that the median interval of NM receiving primary tumor removal and following chemotherapy presented approximately 2.5 times longer than those with only stereotactic surgery (SRS) treatment, which highlighted the following therapy after SRS as soon as possible in order to prevent the metastatic progression.

Considering the wide variations in different age arrays or primary tumors as above mentioned, we continued to deepen the subgroup analysis in terms of age and pathology. As shown in Supplementary Table 1, cases were grouped based on the age. Metastatic sites in children group were more eccentric to leptomeninges. Additionally, the duration from primary to metastatic lesions in pediatric group was the shortest among three populations. And the concurrent NM with primary tumors were also relatively common in children group, of which medulloblastoma was the most common subset, indicating the poorest prognosis in this period. On the other hand, the most five common pathological subgroups of NM were further analyzed including demographic and metastatic parameters (Supplementary Table 2). The male-to-female ratio was highest in patients with GCTs, supporting the evidence that male adolescents progressed more frequently to disseminated status (Supplementary Table 1 and 2). Only the NM from ependymoma exhibited tendency on females. The median duration from initial GCTs to NM was only 8.9 months, dramatically shorter than 
others. Medulloblastoma and ependymoma disseminated more dominantly to the whole leptomeninges, whereas the GCTs, glioma and PPTs showed particular preferences to the ventricular system. Given the significant differences between low- and high-grade glioma, we further divided gliomas into two subgroups. As shown in Supplementary Table 3, based on the shorter duration to NM and higher percentage of coexisting NM, high-grade gliomas significantly tended to disseminate along the neuraxis.

\section{Clinical manifestations on NM onset}

Among the entire participates, $38(19.19 \%)$ cases presented intracranial symptoms and signs and 65 (32.83\%) cases suffered from intraspinal presentations (Table 1). Of others, $58(29.29 \%)$ patients had contaminant NM with primary tumors and 48 (24.24\%) asymptomatic patients were diagnosed incidentally during the following MRI monitor. A variety of clinical manifestations indicated that neuraxis was infiltrated multifocally by NM. As listed in Table 1, the most common symptom was pain including headache $(9 / 38$ cases) and back pain (22/65 cases). Parenchymal and ventricular metastases led to epilepsy (8/38 cases) and ataxia (5/38 cases). Attentively, a consensus had been reached that there was difficulty in distinguishing metastatic from primary manifestations because of the multifocal lesions. Moreover, given a part of patients showed minimal symptoms, suspicious screening should be performed for early diagnosis.

\section{Diagnostic establishment of NM on MRI}

Referring to the NCCN guidelines and Response Assessment in Neuro-oncology Group [19, 21], the identification of NM in our center depended mainly on the Gd-enhanced MRI. As above mentioned, 318 positive MRI results were detected including 149 intracranial NM and 169 intraspinal lesions.

Based on the typical presentations of MRI, we classified the intracranial NM as miliary, procumbent, nodal and massive subtypes (Fig. 3). The standards were described as follows:

$\bigotimes$, the miliary subtype should be identified as the NM on the surface of leptomeninges or ventricular walls in the miliary or filament manner (Fig. 3A);

$\bigotimes$, the procumbent subtype presented as the spreadable and crawled plaque attaching internal walls of lateral ventricles, whose diameter was more than $1 \mathrm{~cm}$ (Fig. 3B);

Q, the character of nodal NM should be defined as the lesions being less than $1 \mathrm{~cm}$ in the nodular shape, which often located in subarachnoid spaces and ventricles (Fig. 3C);

$\bigotimes$, the massive feature was that the diameter of NM with round or oval shape presented larger than $1 \mathrm{~cm}$, which usually sited in the subarachnoid cisterns and ventricles (Fig. 3D). 
Accordingly, the most common intracranial subtype was the massive one (supplementary Fig.1B). There existed a dramatic difference in the coexisting NM rate between the miliary group and the three others ( $54.05 \%$ vs. $23.21 \%$, supplementary Fig. 1B), indicating that the postoperative tumors progressed more commonly to NM in the nodal, procumbent and massive manners. Previously, we had constructed the classification and stage of brain-to-spine NM [22] including the leptomeningeal type ( $L$ type) and nerve root type ( $\mathrm{N}$ type, Fig. 3E-3J). Apart from spreading in the spinal subarachnoid space, 7 cases of the intramedullary metastases (IM type) in the central canal of spinal cord were involved in current database (Fig. 3K). The NM in the miliary subgroup occurred most frequently, followed by the nodal subset (Supplementary Table 4 and Supplementary Fig. 1B). Similar to the intracranial findings, the postoperative intraspinal NM usually showed the nodal and massive features ( $N$ type, Supplementary Fig. 1B).

\section{Treatment for NM}

Among the whole cases, 28 (14.14\%) intracranial and 15 (7.58\%) intraspinal cases underwent operation, 38 (19.19\%) patients received chemotherapy alone, 20 (10.10\%) patients received radiation alone and 110 (55.56\%) patients were treated with combined chemoradiotherapy (Table 1 ).

\section{Operation}

Of the 28 intracranial NM, 24 were removed targeting the bulky masses and 4 cases only received the biopsies. The anterior skull base and lateral ventricles were most commonly involved in the operation regions (Table 1, Fig. 4). Besides, $2 / 3$ of intraspinal NM with $\mathrm{N} \otimes$ type (or the nodal shape) received operation. Taken together, the operative removal for NM was most frequently performed in the nodal subset, followed by the massive subset (Fig. 4).

\section{Chemotherapy}

A total of $148(74.75 \%)$ cases received the intravenous chemotherapy in this study. Regiments were listed in Supplementary Table 5. For the disseminated medulloblastoma, the most commonly applied plan was a triple regiment consisting of ifosfamide (IFO), carboplatin (CBP) and teniposide (VM-26). Cisplatin (DDP) combined with pemetrexed (PEM) and high-dosage methotrexate (HD MTX) was utilized as the rescue strategy in 8 patients. Among the patients with GCTs, the triple therapeutic strategy containing IFO, CBP and etoposide (VP-16) was most commonly applied accounting for $10.61 \%$. HD MTX was mainly adopted for the NM infiltrating the ventricular system. For the metastatic glioma, 23 patients receiving the temozolomide (TMZ) combined with two or three other regiments, such as irinotecan (CTP-11), nimustine (ACNU) and Endostatin. In the ependymal tumors, the triple plan (IFO + CBP + VP-16) was also available for 3/4 patients. For the PPTs, IFO + CBP + VP-16 strategy was utilized most frequently (Supplementary Table 5). 


\section{Radiation}

Radiation was performed in order to reduce the tumor volumes, control the symptoms and banish the CSF obstructions. The plans were shown in Supplementary Table 5. In current study, the craniospinal irradiation (CSI) was performed most commonly, and CSI was also the most frequently concurrent application with chemotherapy $(61 / 110,55.45 \%)$. Patients with disseminated medulloblastoma received most frequently the combined chemo-/radiotherapy.

\section{Survival and prognosis factors of NM patients}

The median OS was 11.6 months (range, $0.5 ~ 83.0$ months). As shown in Fig. 5A, patients with glioma showed the poorest survival $(p<0.001)$. Moreover, patients suffering from the coexisting NM showed the shorter median OS than the non-coexisting group $(p<0.01)$, which suggested the deteriorating condition among the primary patients with concomitant NM (Fig. 5B). The poor OS was detected in both intracranial and intraspinal nodal subgroups (Fig. 5C and 5D). Figure 5E showed that comprehensive management (OP +

$\mathrm{CT}+\mathrm{RT}$ ) contributed to the better survival by analyzing the comparable data of different treatment options ( $\mathrm{p}$ $<0.01)$.

Furthermore, Cox proportional hazard regression model revealed that the younger age ( $<15$ years), concomitant NM with primary tumors, interval to NM ( $<1$ year), LM and the nodal subset were significantly associated with the poor prognosis (Supplementary Table 6). The 12-month survival rate was $44.32 \%$, and of these 39 patients, 10 (25.64\%) patients lived for longer than 36 months. The mean duration to NM, the incidence rate of GCTs and the ratio of LM exhibited higher levels in patients who survived more than 12 months (Supplementary Table 7). The ratio of operation alone to comprehensive treatment stayed at the higher condition among the patients with $<12$-month survival emphasizing the importance of interdisciplinary management (Supplementary Table 7).

\section{Discussion}

Though a majority of studies regarding the cancer metastases in CNS have been previously published, these are limited to systemic cancers or LM from a fraction of CNS tumors, which makes comprehensive understanding of neuraxis dissemination difficult. The leptomeninges refers to the inner two membranous layers enveloping the brain: the arachnoid membrane and the pia mater $[23,24]$. Thus, LM only represents the involvement of subarachnoid space and leptomeninges without extension to the whole nervous system. Moreover, it is important to note that the concept of neuraxis in current study contains the leptomeninges, ventricular system and cerebrospinal parenchyma. Havingrealized that, we continuously extracted three disseminating routes of cancer cells along the neuraxis, which include (1) the closely direct invasion arising from contiguous tumor deposits to the leptomeninges or subependymal tissues, (2) the centripetal migration through perineural or perivascular spaces, and (3) the spreading to CSF during operation because of the drops from primary tumors $[5,22]$. 
NM are diagnosed in 1 2\% of patients with brain tumors [25], consistent with our data about the incidence rate in about ten years. Both malignant and benign tumors can involve the neuraxis including 32 histopathological subgroups in current study. Metastases as the terminal stage usually occur in progressive cancers. However, NM from CNS tumors often occur concomitantly with primary tumors and even the coexistence is highly suggestive of poor prognosis. Despite metastases occupy $27.5 \%$ of pediatric patients with some common cancers according to the United States Surveillance, Epidemiology and End Results database [26], our findings reveal that disseminated lesions from CNS tumors in children group represent about $48.48 \%$. It is extensively different from the systematic metastases occurring more prevalently in the old population [27].

Previous analyses have reported the median survival is 3 to 7 months across the patients with LM arising from systematic cancers $[18,28]$. In current series, patients from CNS neoplasms achieved the median OS with 11.6 months, because we excluded the cases who only received supportive care. In addition, the poor survival of patients suffering from concomitant NM with primary tumors provides the evidence that NM dramatically contributes to the malignant progression of brain tumors. Similarly, Chamberlain MC and Brower JV also discussed that the coexistent bulky metastases with LM resulted in the short median survival, which was consistent with our knowledge of NM $[29,30]$.

The diagnosis of NM remains challenging without one single tool presenting sufficiently sensitive to figure out metastases. In current study, we highlight the radiographic classification based on MRI presentations, which is non-aggressive and intuitionistic for patients and established well for the prognostic assessment. Importantly, the sensitivity and specificity of enhanced MRI can reach approximately $70 \%$ and $77 \%$, respectively [31]. Some previous studies only classified intracranial metastases of glioma [32, 33]. Herein, all kinds of NM cases are submitted to the classification system by interpreting the MRI characters (Fig. 1). However, the CSF examination data is not analyzed in current workup such as the lumbar pressure, cell counts and concentration of protein. The reasons are listed as follows, (1) These indexes vary at different levels and the low sensitivity and specificity of CSF cytology restrict the diagnostic value in clinical practice [34]. (2) It is unnecessary for the recurrent or metastatic patients with confirmed pathology to make differential diagnosis via CSF cytological analysis. In future study, we are collecting the CSF to identify the ctDNA of malignant cells and analyze the association to genome of NM, which will make sense to detect the underlying molecular mechanism involved in tumorigenesis of NM.

Although the treatment for NM remains palliative for lots of patients, it is clear that effective management can protect from further neurological deterioration. Survival analysis based on the different therapeutic strategies in current study emphasized the importance of tumor resection. Therefore, the surgical indications for NM in our center are determined as follows,

1. To identify the histopathology of tumors

(1) NM are relatively safe for operation or biopsy, given the high risk of dissemination comes from the resection of weeny primary tumors. 
(2) NM are the large uni-focus, when primary tumors have been reduced significantly or disappeared after experiential chemo-/radiotherapy.

2. To relive the massive effect

(1) NM is insensitive to the chemo-/radiotherapy, when primary tumors are under control.

(2) NM are grouped as the nodal or massive subsets based on MRI features.

(3) NM locate at the relatively safe anatomical regions, such as the anterior skull base and cerebellopontine angle.

Additionally, due to the promising effects of intravenous chemotherapy in this study, we summarize some experiences as follows,

(1) The systematic application of anti-neoplastic regiments varies depending on histological and genetic type of NM and the triple scheme of IFO + CBP + VP-16/VM-26 is recommended to NM except glioma.

(2) DDP combined with PEM and HD MTX plays a critical role in suppressing the refractory NM as the rescue strategy.

(3) HD MTX should be adapted to the patients with NM in ventricular system.

(4) NM residues after the whole circles of chemotherapy can be submitted to locoregional management, such as operation, cyberknife or intensity modulated radiation.

\section{Conclusions}

In summary, NM is one of most complicated disease concerning the diagnostic inefficiency, controversial therapies and poor prognosis. First, a number of CNS tumors have the potential of developing to NM. Secondly, prognostic factors including the younger age, coexistence of NM with primary tumors, shorter interval from primary disorder to metastases, high-grade glioma, leptomeningeal seeding and the nodal subtype are significantly associated with the poor outcomes. Thirdly, Gd-MRI findings contribute to promoting the diagnostic accuracy and classification based on MRI patterns provides referential clues to make therapeutic decision and evaluate prognosis. Finally, interdisciplinary management with respect to operation and chemo-/radiotherapy is recommended thereby improving outcomes.

\section{Abbreviations}

CNS, central nervous system; MRI, magnetic resonance imaging; PET/CT, positron emission tomography / computed tomography; GCTs, germinal cell tumors; PPTs, pineal parenchymal tumors; CSF, cerebrospinal fluid; NCCN, National Comprehensive Center Network; CT, chemotherapy; RT, radiotherapy; OP, operation; PCNSL, primary central nervous system lymphoma.

\section{Declarations}




\section{Ethical approval and consent to participate}

All procedures for clinical medical research about human subjects were approved by the Research Ethics Committee of our institute and the written informed consent was obtained from each patient (or the children guardians) included in the current study.

\section{Consent for publication}

Written consent for publication was obtained from all the patients involved in the study.

\section{Availability of data}

Please contact the corresponding author for the data requests.

\section{Competing interests}

The authors in this article declare that they have no potential conflict of interests.

\section{Funding}

This work was supported by the Beijing Municipal Science \& Technology Commission Grant (Z151100004015165, to Zhang MS), National Natural science foundation of China (81902975, to Liu HL) and Scientific Research Common Program of Beijing Commission of Education Grant (KM201610025027, to Gu CY).

\section{Author contributions}

Zhang MS and Liu HL conceived the study. Zhang JP, Li C and Wang HR contributed to the collection of samples and data. Liu HL, Liu YQ, Ma Q and Sun YL performed the data analyses. Liu HL and Zhang MS drafted the manuscript, Yu CJ, Gu CY and Zhang HW gave critical revision to it.

\section{Acknowledgment}

Acknowledgment should be owed to Ichiro Nakano at Department of Neurological Surgery of The Ohio State University and Zeng-Jie Yang at Fox Chase Cancer Center for the thoughtful comments. The authors also would like to thank Xueling Qi and Kun Yao at Department of Neuropathology of Sanbo Brain Hospital Capital Medical University for the pathological estimates as well as Mingwang Zhu at Department of Neuroradiology of Sanbo Brain Hospital Capital Medical University for the neuroimaging interpretations.

\section{References}

1. Chen W, Zheng R, Baade PD, et al. Cancer statistics in China, 2015. CA Cancer J Clin. 2016;66:115-32.

2. Gleissner B, Chamberlain MC. Neoplastic meningitis. Lancet Oncol. 2006;5:443-52. 
3. Wang N, Bertalan MS, Brastianos PK. Leptomeningeal metastasis from systemic cancers: review and update on management. 2018;124:21-35.

4. Hyun JW, Jeong IH, Joung AR, et al. Leptomeningeal metastasis: clinical experience of 519 cases. Eur J Cancer. 2016;56:107-14.

5. Kesari S, Batchelor TT. Leptomeningeal metastases. Neurol Clin N Am. 2003;21(5):25-66.

6. Bordignon KC, Neto MC, Ramina R, et al. Patterns of neuraxis dissemination of gliomas: suggestion of a classification based on magnetic resonance imaging findings. Surg Neurol. 2006;65:472-77.

7. Gangadhar K, Santhosh D. Radiopathlogical evaluation of primary malignant skull tumors: a review. Clin Neurol Neurosurg. 2012;114:833-39.

8. Clarke JL, Perez HR, Jacks LM, Panageas KS, Deangelis LM. Leptomeningeal metastases in the MRI era. Neurology. 2010;74:1449-54.

9. Zhang MS, Wang ZY, Zhang JP, Zhang HW, Gu CY, Wang HR, et al. Metastases in cerebellopontine angle from the tumors of the central nervous system. J Clin Neurosci. 2017;42:84-90.

10. Barajas RF, Cha S. Metastasis in adult brain tumors. Neuroimage Clin N Am. 2016;26:601-20.

11. Faria AV, Azevedo GA, Zanardi VA, Ghizoni E, Queiroz LS. Dissemination patterns of pilocytic astrocytoma. Clin Neurol Neurosurg. 2006;108:568-72.

12. Beauchesne P. Intrathecal chemotherapy for treatment of leptomeningeal dissemination of metastatic tumors. Lancet Oncol. 2010;11:871-9.

13. Herrlinger U, Foschler H, Kuker W, Meyermann R, Bamberg M, Dichgans J, et al. Leptomeningeal metastasis: survival and prognostic factors in 155 patients. J Neurolog Sci. 2004;223:167-78.

14. Umemura S, Tsubouchi $\mathrm{K}$, Yoshioka $\mathrm{H}$, et al. Clinical outcome in patients with leptomeningeal metastasis from non-small cell lung cancer: okayama Lung Cancer Study Group. Lung Cancer. 2012;77:134-39.

15. Assi HI, Mahmoud T, Saadeh FS, Darsa HE. Management of leptomeningeal metastasis in breast cancer. Clin Neurol Neurosurg. 2018;172:151-59.

16. Tremont-Lukats IW, Bobustuc G, Lagos G, Lolas K, Kyritsis AP, Puduvalli VK. Brain metastasis from prostate carcinoma: the M.D. Anderson Cancer Center experience. 2003;15:363-68.

17. Oechsle K, Lange-Brock V, Kruell A, Bokemeyer C, Wit MD. Prognostic factors and treatment options in patients with leptomeningeal metastases of different primary tumors: a retrospective analysis. $J$ Cancer Res Clin Oncol. 2010;136:1729-35.

18. Waki F, Ando M, Takashima A, Yonemori K, Nokihara H, Miyake M, Tateishi U, et al. Prognostic factors and clinical outcomes in patients with leptomeningeal metastasis from solid tumors. J Neurooncol. 2009;93:205012.

19. Nabors LB, Porthow J, Ammirati M, Baehring J, Brem H, Brown P, Butowski N, et al Central nervous system cancers, version 1. 2015. J Natl Compr Canc Netw. 2015;13:1191-202.

20. Cheng HY, Perez-Soler R. Leptomeningeal metastases in non-small-cell lung cancer. Lancet Oncol. 2018;19:e43-55.

21. Chamberlain MC, Junck L, Brandsma D, et al. Leptomeningeal metastases: a RANO proposal for response criteria. Neuro Oncol. 2017;19:484-92. 
22. Zhang MS, Ou YW, Zhang HW, Zhang JP, Xia L, Qu YM, et al. Leptomeningeal metastases from central nervous system tumors: a study of classification and stage in the spinal cord of 58 patients. Chin Sci Bull. 2012;57:2914-19.

23. Sanan A, van Loveren HR. The arachnoid and the myth of Arachne. 1999;45:152-5.

24. Haines DE, Frederickson GR. The meninges. In: Al-Mefty O. Meningiomas. New York, Raven Press, 1991, pp 9-25.

25. Chamberlain MC. Neoplastic meningitis. J Clin Oncol. 2005;23:3605-13.

26. Stephanie M. Perkins, Eric T. Shinohara, Todd DeWee, Haydar Frangoul. Outcome for children with metastatic solid tumors over the last four decades. Plos One. 2014;9:e1000396.

27. US Department of Health and Human Service, US National Institute of Health, US National Cancer Institute, Adolescent and Young Adult Oncology Progress Report Group, eds. Closing the gap: research and care imperative for adolescents and young adults with cancer; 2015.

28. Herrlinger $U$, Forschler $H$, Kuker W, Meyermann R, Bamberg $M$, et al. Leptomeningeal metastasis: survival and prognostic factors in 155 patients. $J$ Neurosurg Sci. 2004;223:167-78.

29. Brower JV, Saha S, Rosenberg SA, Hullett CR, Robins HI. Management of leptomeningeal metastases: prognostic factors and associated outcomes. J Clin Neurosci. 2016;27:130-37.

30. Groves MD. New strategies in the management of leptomeningeal metastasis. Arch Neurol. 2010;67:30512.

31. Chamberlain MC, Glantz M, Grove MD, Wilson WH. Diagnostic tools for neoplastic meningitis: detecting disease, identifying patient risk, and determining benefit of treatment. Semin Oncol. 2009;36:S35-S45.

32. Gururangan S, McLaughlin CA, Brashear J, Watral MA, Provenzale J, Coleman RE, et al. Incidence and patterns of neuraxis metastases in children with diffuse pontine glioma. J Neurooncol. 2006;77:207-12.

33. Chamberlain MC, Soffietti R, Raizer J, Ruda R, Brandsma D, Boogerd W, et al. Leptomeningeal metastasis: a Response Assessment in Neuro-Oncology critical review of endpoints and response criteria of published randomized clinical trials. Neuro Oncol. 2014;16:1176-85.

34. O'Meara WP, Borkar SA, Stambuk HE, Lymberis SC. Leptomeningeal metastasis. Curr Prob/ Cancer. 2007;31:367-424.

\section{Tables}

Table 1 

N (\% of
all
N (\% of
cases)
cases)

\begin{tabular}{lll} 
Gender & & Symptoms and signs \\
Male & 133 & Intracranial \\
& $(67.17)$ & \\
\hline
\end{tabular}

\begin{tabular}{llll} 
Female & $\begin{array}{l}65 \\
(32.83)\end{array}$ & Headache & $\begin{array}{l}9 \\
(4.55)\end{array}$ \\
\hline Age & & Epilepsy & $\begin{array}{l}8 \\
(4.04)\end{array}$ \\
\hline$<15$ y & & & 5 \\
& $\begin{array}{l}96 \\
(48.48)\end{array}$ & Ataxia & $(2.53)$ \\
\hline $15 y$ & $\begin{array}{l}102 \\
(51.52)\end{array}$ & Vomiting & 5 \\
\hline
\end{tabular}

\begin{tabular}{|ll} 
Primary tumors & Blurred vison \\
\hline Embryonal tumors & Tinnitus \\
\hline
\end{tabular}

\begin{tabular}{|c|c|c|c|}
\hline Medulloblastoma & $\begin{array}{l}68 \\
(34.34)\end{array}$ & Hearing loss & $\begin{array}{l}2 \\
(1.01)\end{array}$ \\
\hline PNET & $\begin{array}{l}6 \\
(3.03)\end{array}$ & Dizziness & $\begin{array}{l}2 \\
(1.01)\end{array}$ \\
\hline AT / RT & $\begin{array}{l}2 \\
(1.01)\end{array}$ & Bucking & $\begin{array}{l}1 \\
(0.51)\end{array}$ \\
\hline Esthesioneuroblastoma & $\begin{array}{l}2 \\
(1.01)\end{array}$ & Diplopia & $\begin{array}{l}1 \\
(0.51)\end{array}$ \\
\hline GCTs & & Intraspinal & \\
\hline Mixed GCTs & $\begin{array}{l}21 \\
(10.61)\end{array}$ & Back pain & $\begin{array}{l}22 \\
(11.11)\end{array}$ \\
\hline Germinomas & $\begin{array}{l}17 \\
(8.59)\end{array}$ & $\begin{array}{l}\text { Extremity } \\
\text { weakness }\end{array}$ & $\begin{array}{l}17 \\
(8.59)\end{array}$ \\
\hline Glioma & & $\begin{array}{l}\text { Extremity } \\
\text { numbness }\end{array}$ & $\begin{array}{l}16 \\
(8.08)\end{array}$ \\
\hline Glioblastoma & $\begin{array}{l}15 \\
(7.58)\end{array}$ & Extremity ache & $\begin{array}{l}7 \\
(3.54)\end{array}$ \\
\hline Astrocytic tumors & & $\begin{array}{l}\text { Bowel / bladder } \\
\text { dysfunction }\end{array}$ & $\begin{array}{l}6 \\
(3.03)\end{array}$ \\
\hline Astrocytoma & $\begin{array}{l}7 \\
(3.54)\end{array}$ & Ataxia & $\begin{array}{l}4 \\
(2.02)\end{array}$ \\
\hline Anaplastic & 2 & Impotence & 1 \\
\hline & & Page $14 / 21$ & \\
\hline
\end{tabular}


astrocytoma

(1.01)

(0.51)

\begin{tabular}{|c|c|c|c|}
\hline Astroblastoma & $\begin{array}{l}1 \\
(0.51)\end{array}$ & Treatment & \\
\hline $\begin{array}{l}\text { Pilocytic } \\
\text { astrocytoma }\end{array}$ & $\begin{array}{l}3 \\
(1.52)\end{array}$ & Operation for NM & \\
\hline $\begin{array}{l}\text { Oligodendroglial } \\
\text { tumors }\end{array}$ & & Intracranial & \\
\hline $\begin{array}{c}\text { Anaplastic } \\
\text { oligodendroglioma }\end{array}$ & $\begin{array}{l}1 \\
(0.51)\end{array}$ & Approaches & \\
\hline Oligodendroglioma & $\begin{array}{l}1 \\
(0.51)\end{array}$ & Removal & $\begin{array}{l}24 \\
(12.12)\end{array}$ \\
\hline $\begin{array}{l}\text { Astrocytic and } \\
\text { oligodendroglia tumors }\end{array}$ & & Biopsy & $\begin{array}{l}4 \\
(2.02)\end{array}$ \\
\hline $\begin{array}{c}\text { Astrocytic- } \\
\text { oligodendroglioma }\end{array}$ & $\begin{array}{l}1 \\
(0.51)\end{array}$ & Sites & \\
\hline $\begin{array}{l}\quad \text { Anaplastic } \\
\text { Astrocytic- } \\
\text { oligodendroglioma }\end{array}$ & $\begin{array}{l}4 \\
(2.02)\end{array}$ & base $\quad$ Antieror skull & $\begin{array}{l}6 \\
(3.03)\end{array}$ \\
\hline Ependimal tumors & & $\begin{array}{l}\text { Lateral } \\
\text { ventricles }\end{array}$ & $\begin{array}{l}6 \\
(3.03)\end{array}$ \\
\hline $\begin{array}{r}\text { Anaplastic } \\
\text { ependimoma }\end{array}$ & $\begin{array}{l}9 \\
(4.55)\end{array}$ & $\begin{array}{l}\text { Third } \\
\text { ventricles }\end{array}$ & $\begin{array}{l}4 \\
(2.02)\end{array}$ \\
\hline Ependimoma & $\begin{array}{l}6 \\
(3.03)\end{array}$ & CPA & $\begin{array}{l}4 \\
(2.02)\end{array}$ \\
\hline PPTs & & $\begin{array}{l}\text { Cerebral } \\
\text { hemisphere }\end{array}$ & $\begin{array}{l}2 \\
(1.01)\end{array}$ \\
\hline PPTID & $\begin{array}{l}6 \\
(3.03)\end{array}$ & $\begin{array}{l}\text { Cerebellar } \\
\text { hemisphere }\end{array}$ & $\begin{array}{l}2 \\
(1.01)\end{array}$ \\
\hline Pineoblastoma & $\begin{array}{l}4 \\
(2.02)\end{array}$ & 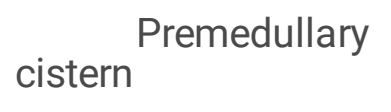 & $\begin{array}{l}2 \\
(1.01)\end{array}$ \\
\hline Choroid plexus tumors & & $\begin{array}{l}\text { Suprasellar } \\
\text { cistern }\end{array}$ & $\begin{array}{l}1 \\
(0.51)\end{array}$ \\
\hline $\begin{array}{l}\text { Choroid plexus } \\
\text { carcinoma }\end{array}$ & $\begin{array}{l}3 \\
(1.52)\end{array}$ & magna & $\begin{array}{l}1 \\
(0.51)\end{array}$ \\
\hline $\begin{array}{l}\text { Atypical choroid } \\
\text { plexus papilloma }\end{array}$ & $\begin{array}{l}1 \\
(0.51)\end{array}$ & Intraspinal & \\
\hline $\begin{array}{l}\text { Choroid plexus } \\
\text { papilloma }\end{array}$ & $\begin{array}{l}1 \\
(0.51)\end{array}$ & $\mathrm{L} \bigotimes \mathbf{a}$ & $\begin{array}{l}1 \\
(0.51)\end{array}$ \\
\hline $\begin{array}{l}\text { Tumors of the sellar } \\
\text { region }\end{array}$ & & $\mathrm{L} \bigotimes \mathrm{b}$ & $\begin{array}{l}2 \\
(1.01)\end{array}$ \\
\hline
\end{tabular}

$\mathrm{N} \otimes$ 


\begin{tabular}{|c|c|c|c|}
\hline Pituitary adenoma & & $\mathrm{N} \Downarrow \mathrm{a}$ & $\begin{array}{l}1 \\
(0.51)\end{array}$ \\
\hline $\begin{array}{l}\text { Nonfunctional } \\
\text { pituitary adenoma }\end{array}$ & $\begin{array}{l}2 \\
(1.01)\end{array}$ & Intramedullary & $\begin{array}{l}1 \\
(0.51)\end{array}$ \\
\hline $\begin{array}{l}\text { Growth hormone } \\
\text { pituitary adenoma }\end{array}$ & $\begin{array}{l}1 \\
(0.51)\end{array}$ & Chemo-/radiotherapy & \\
\hline Meningiomas & & CT alone & $\begin{array}{l}38 \\
(19.19)\end{array}$ \\
\hline $\begin{array}{l}\text { Anaplastic } \\
\text { meningioma }\end{array}$ & $\begin{array}{l}1 \\
(0.51)\end{array}$ & RT alone & $\begin{array}{l}20 \\
(10.10)\end{array}$ \\
\hline $\begin{array}{l}\text { Rhabdoid } \\
\text { meningioma }\end{array}$ & $\begin{array}{l}2 \\
(1.01)\end{array}$ & $\mathrm{CT}+\mathrm{RT}$ & $\begin{array}{l}110 \\
(55.56)\end{array}$ \\
\hline PCNSL & $\begin{array}{l}5 \\
(2.53)\end{array}$ & Prognosis & \\
\hline $\begin{array}{l}\text { Malignant } \\
\text { schwannoma }\end{array}$ & $\begin{array}{l}1 \\
(0.51)\end{array}$ & Death & $\begin{array}{l}98 \\
(61.63)\end{array}$ \\
\hline Melanoma & $\begin{array}{l}1 \\
(0.51)\end{array}$ & Alive & \\
\hline Neuronal-glial tumor & $\begin{array}{l}1 \\
(0.51)\end{array}$ & Improved & $\begin{array}{l}38 \\
(23.90)\end{array}$ \\
\hline others & & Stabled & $\begin{array}{l}16 \\
(10.06)\end{array}$ \\
\hline $\begin{array}{l}\text { Small cell malignant } \\
\text { tumor }\end{array}$ & $\begin{array}{l}1 \\
(0.51)\end{array}$ & Progressed & $\begin{array}{l}7 \\
(4.40)\end{array}$ \\
\hline
\end{tabular}

NM, neuraxis metastases; PPTs, pineal parenchymal tumors; PPTID, pineal parenchymal tumor of intermediate differentiation; PCNSL, primary central nervous system lymphoma; CT, chemotherapy; RT, radiotherapy; CPA, cerebellopontine angle.

\section{Figures}




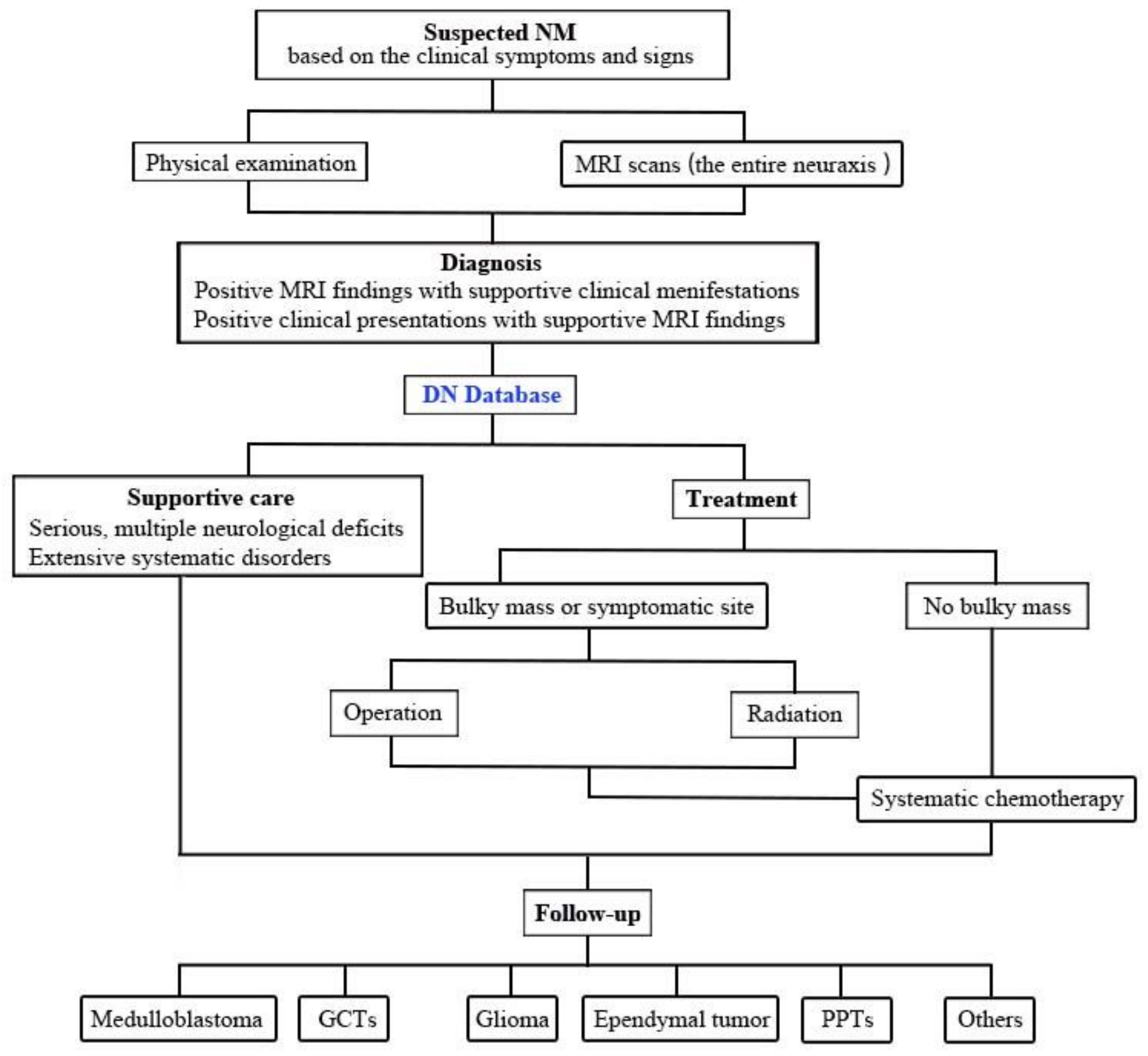

Figure 1

\section{Figure 1}

The initial workup for NM. The patients suspected with NM should be evaluated according to the neurological examination and MRI scans, then the confirmed NM cases would be included into the NM database and receive the corresponding treatment and follow-up. 
A

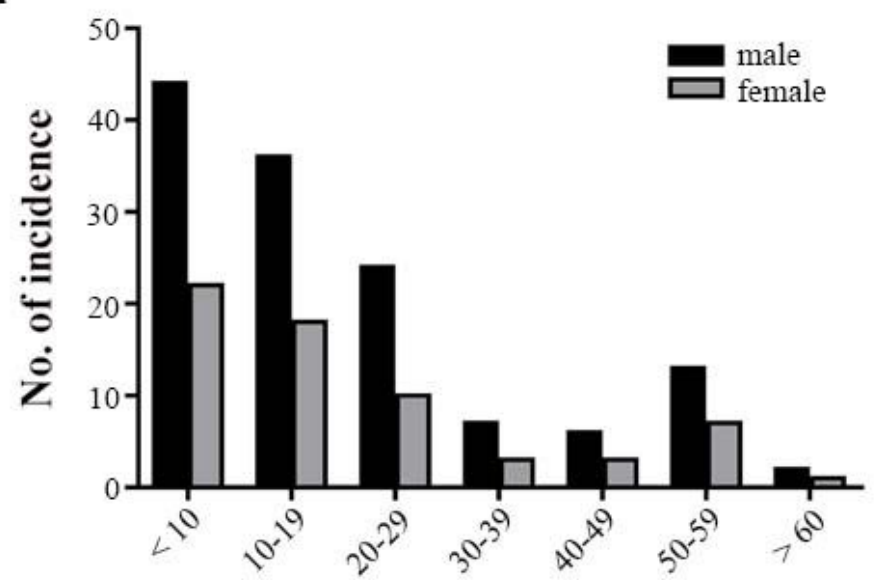

B

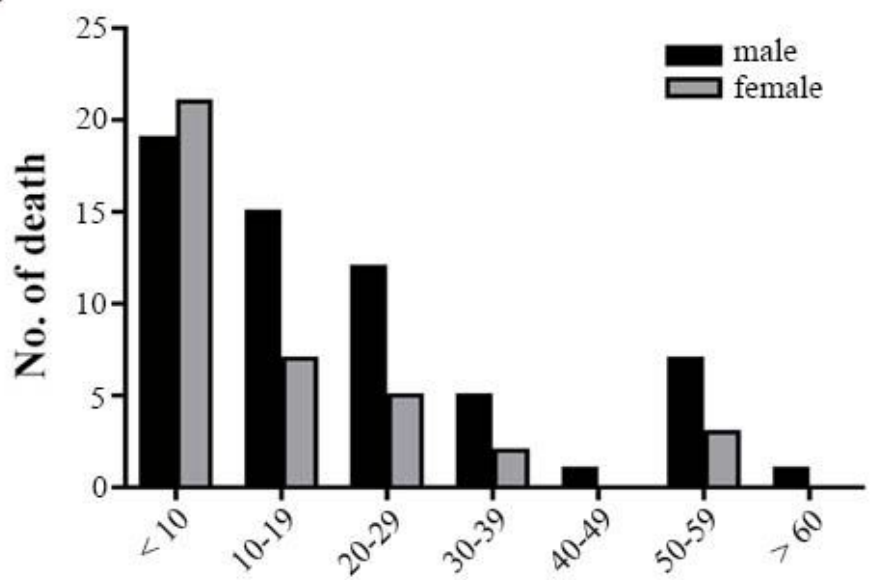

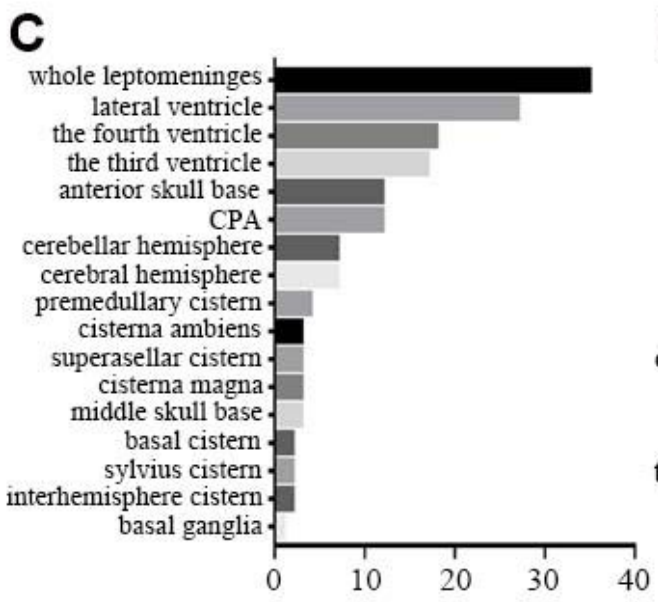
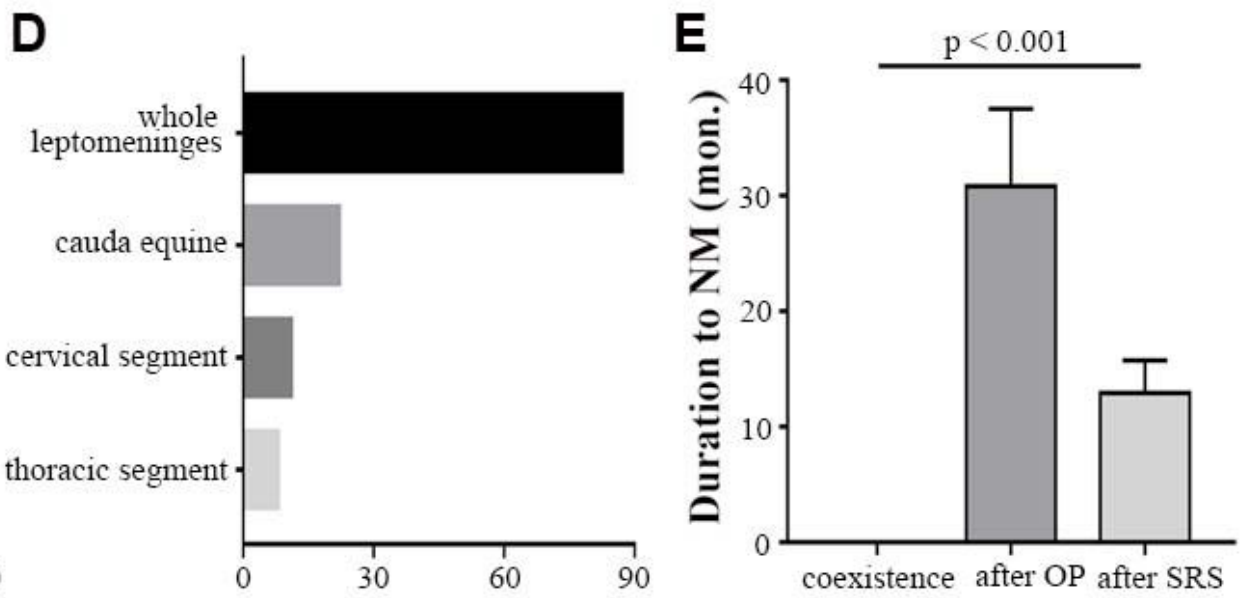

Figure 2

\section{Figure 2}

Epidemiological distribution in this cohort of cases. A. The incidence of NM scaled by gender distributed in seven age groups from $<10$ years to $>60$ years. B. The mortality cases of NM divided into seven age groups from $<10$ years to $>60$ years. C. The incidence of metastatic lesions presented in different cranial (left) and spine (right) sites. D. The interval from primary tumor removal to NM onset. 

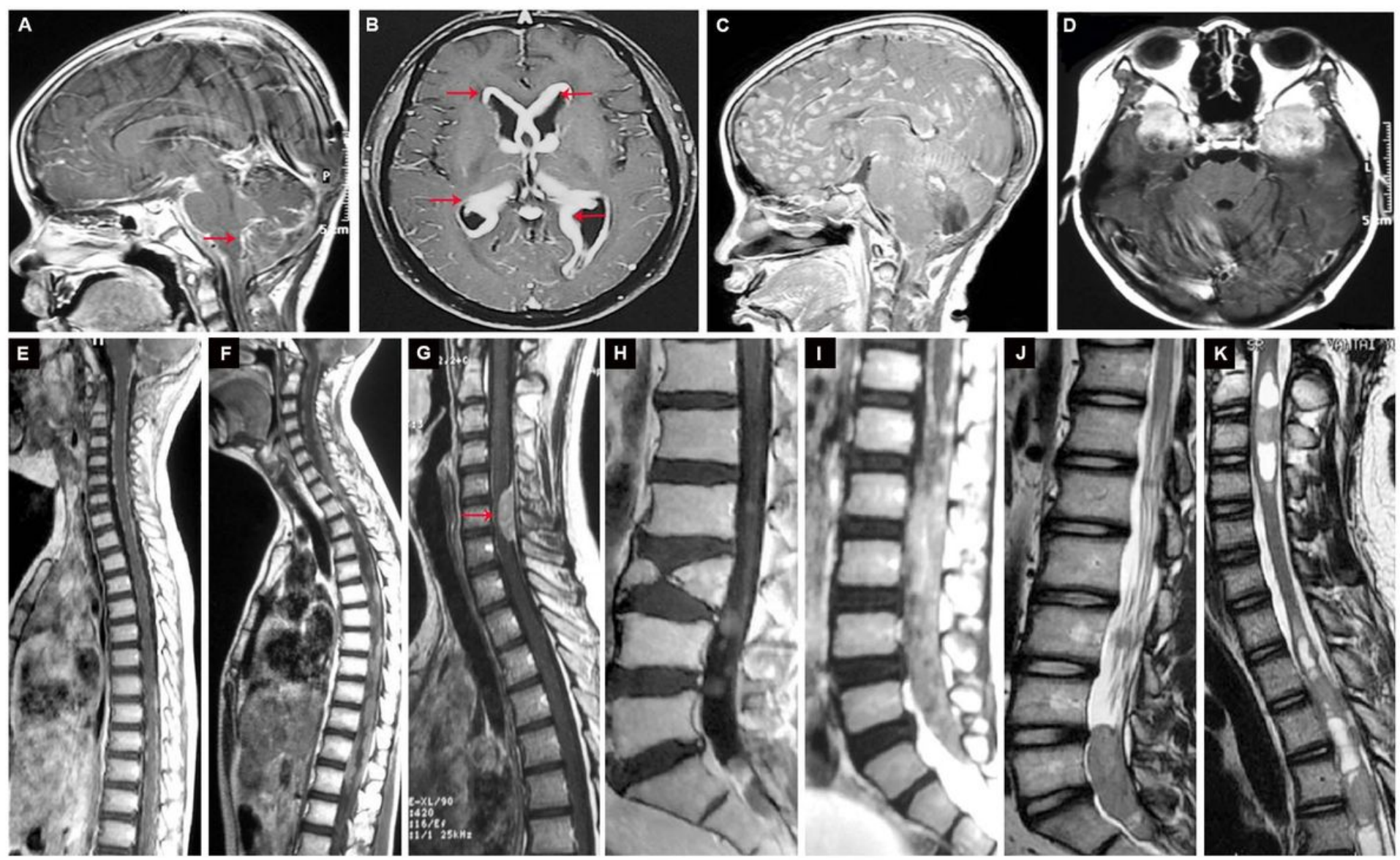

Figure. 3

\section{Figure 3}

Representative radiographic panel of NM classification. A-D. The intracranial NM subtypes. A, the sagittal T1WI with enhancement showing the disseminated medulloblastoma on the surface of leptomeninges as the filament pattern (red arrow). B, the axial enhanced T1WI displaying the procumbent-shape metastatic glioma located at the internal walls of the lateral ventricle (red arrow). C, the sagittal contrasted T1WI showing lots of nodular metastases in the subarachnoid spaces which were less than $1 \mathrm{~cm}$. D, the axial T1WI with enhancement presenting the two massive round metastatic anaplastic ependymomas in the subarachnoid cisterns. E-K. The intraspinal NM subtypes. E, the sagittal whole spine MRI showing the LI subtype, the leptomeningeal linear enhancement with diffuse miliary medulloblastoma. F, the sagittal T1WI with contrast exhibiting the metastatic medulloblastoma with extensive distribution in the cervical, thoracic and lumber leptomeninges, classified as the Llla subgroup. G, the sagittal cervical MRI with enhancement showing the LIlb subtype, which was located in the procumbent pattern with a narrow base in the subarachnoid space of C5-C7 level (red arrow). $\mathrm{H}$, the sagittal enhanced T1WI displaying the multiple nodular NM located in the cauda equine, classified as the NI subtype. I, the sagittal T2WI showing the giant metastasis with irregular boundary filling the entire lumber and sacral canal, identified as the NIla subtype. J, the sagittal T2WI presenting the NIIb NM as the massive tumor with distinct borders in the sacral canal. K, the sagittal T2WI showing some intramedullary metastases in the cervical and thoracic spinal cord. 

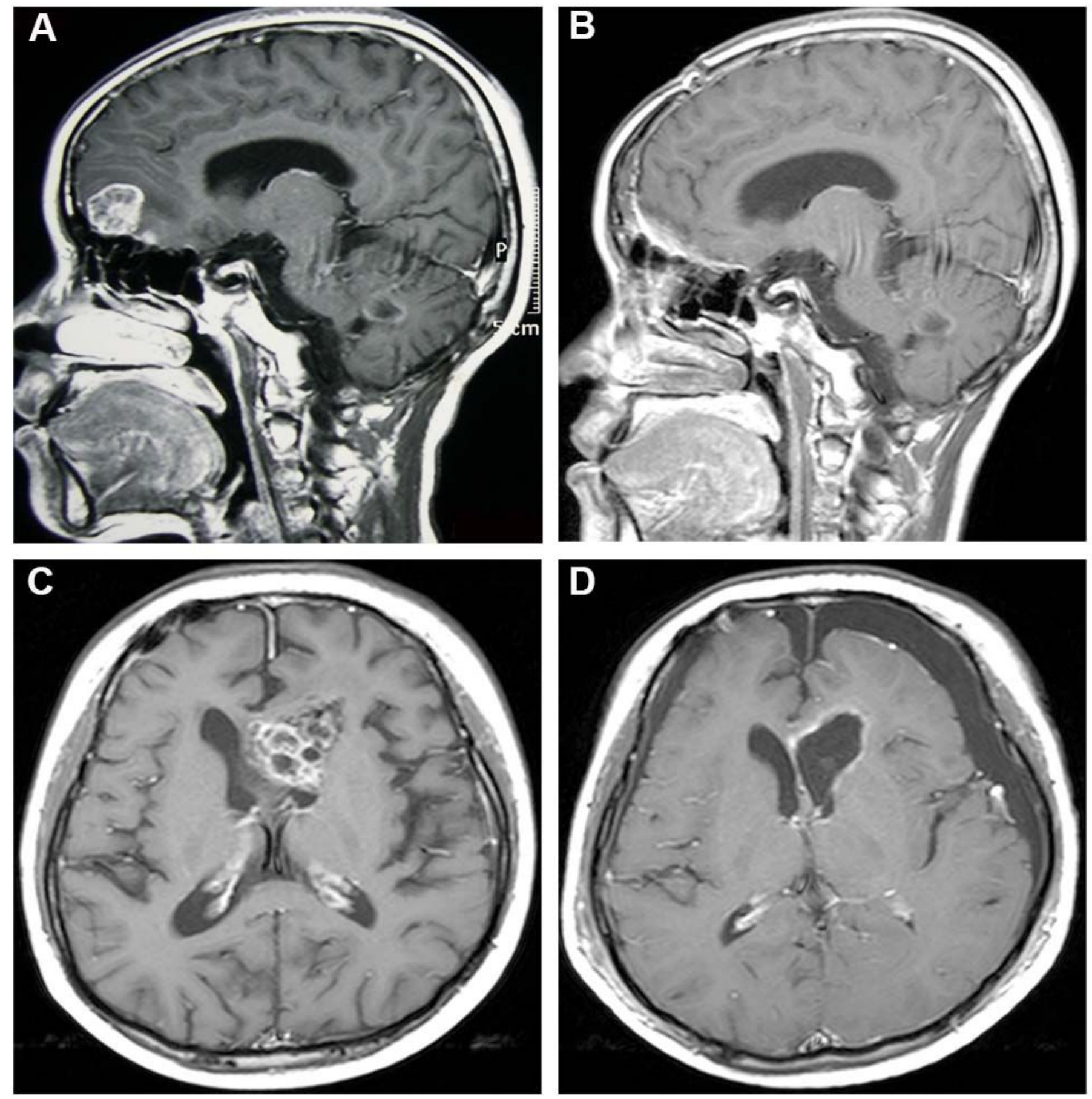

Figure. 4

\section{Figure 4}

Representative neuroimages of two cases with NM receiving operations. A-B. A case suffering from the disseminated medulloblastoma with the massive subtype in the anterior skull base (A) received the gross total removal of NM (B). C-D. A case with metastatic glioma in the left lateral ventricle (C) received the gross total resection of NM (D). 
A
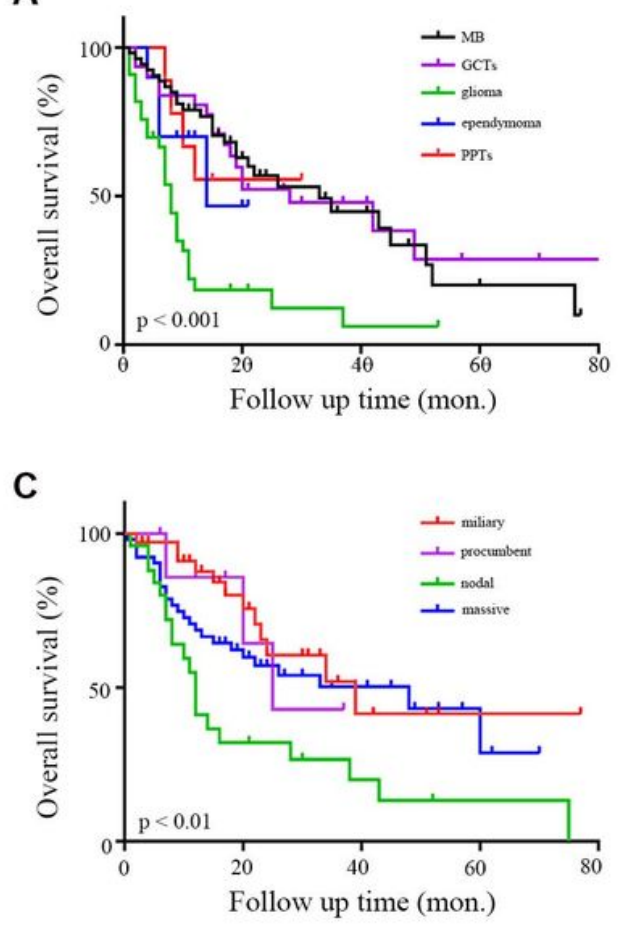

B

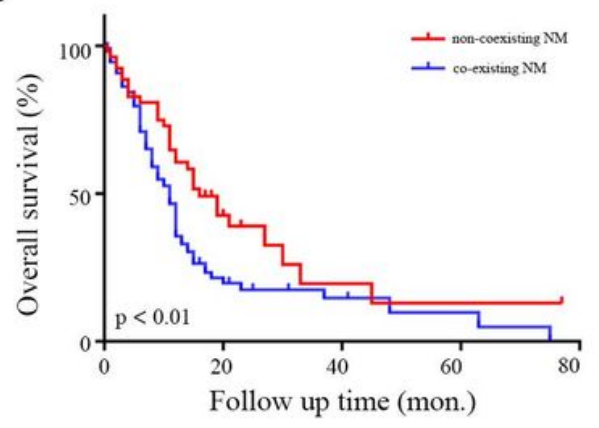

D
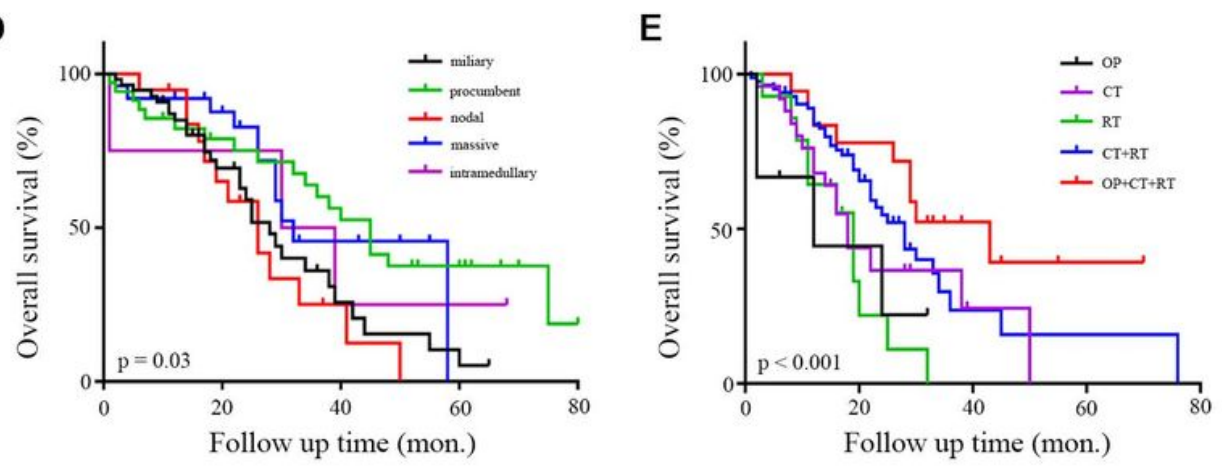

Figure 5

\section{Figure 5}

Survival analysis by Kaplan-Meier estimates A. The survival of patients with glioma was poorer than the other groups. B. Patients without concurrent NM had a longer survival than the coexistence. C. The survival of patients in the nodal intracranial group was shorter than that in the other groups. D. The patients with intraspinal NM in the nodal subset showed the poor survival compared with other subgroups. E. Patients receiving comprehensive treatment $(\mathrm{OP}+\mathrm{CT}+\mathrm{RT})$ presented the better overall survival benefit than others.

\section{Supplementary Files}

This is a list of supplementary files associated with this preprint. Click to download.

- stable6.xls

- stable5.xls

- stable7.xls

- Sfigure1.tif

- stable4.xls

- stable2.xls

- stable3.xls

- stable1.xls 